\title{
Redox Reaction of Ferritin Immobilized onto SAMs- and Polypeptides-Modified Electrodes
}

\author{
Masato Tominaga \\ Graduate School of Science and Technology, Kumamoto University, \\ 2-39-1, Kurokami, Kumamoto 860-8555, Japan
}

Received August 19, 2010

\begin{abstract}
Electrode reactions of ferritin-immobilized electrodes based on both self-assembled monolayers (SAMs)-modified gold and polypeptides-modified ITO electrodes were investigated. It was observed that during the redox reactions, the total charge in the ferritin cavity would be necessary to compensate for changes in the charge of the ferritin cavity; in other words, to maintain electroneutrality in the cavity. Ion uptake and/or release passing through the ion channels of the ferritin molecule would be the rate-determining factor. Thus, the redox reactions of ferritin were also strongly influenced by the fine structural changes of the ion channel induced by the ambient temperature and the binding of the ferritin molecule with polypeptides via electrostatic interactions. The redox reactions of ferritin represent a typical model of nano-space electrochemistry.
\end{abstract}

Keywords: ferritin, polypeptide, ITO, self-assembled monolayer (SAM), iron ion

\section{Introduction}

Ferritin provides a means for living systems to gain access to essential mineral nutrients under conditions that would otherwise favor the formation of hydrous ferric oxide, a biologically inert form of iron. Ferritins consist of protein shells formed from highly-symmetrical subunits, and from mineral cores containing up to $c a .4500$ iron atoms in the form of ferrihydrite phosphate, $(\mathrm{FeOOH})_{8}\left(\mathrm{FeOPO}_{3} \mathrm{H}_{2}\right)^{1-9)}$. The outside diameter of the shell is $c a .12 \mathrm{~nm}$, and the cage that surrounds the hollow cavity is roughly $8 \mathrm{~nm}$ in diameter. Eight hydrophilic 3-fold channels and six hydrophobic 4-fold channels surround the shell, which provide access to the protein interior, presumably for electrons, protons, small ions and molecules. The 3-fold channels are proposed to be the main entry route for iron ${ }^{1-9)}$. The iron uptake and release mechanisms are caused by iron $(\mathrm{Fe}(\mathrm{III}) / \mathrm{Fe}(\mathrm{II}))$ redox reactions ${ }^{1-9)}$. In an earlier 
study, it was hypothesized that only small-sized reductants such as dithionite could possibly enter the protein shell and react with $\mathrm{Fe}(\mathrm{III})^{1)}$. However, it was clear that larger reductants such as $\mathrm{FMNH}_{2}, \mathrm{NADH}$ and cytochrome $\mathrm{c}$ that were too large to pass through the ion channel on the protein shell could also react as reducing agents for the $\mathrm{Fe}(\mathrm{III})$ in the protein $\operatorname{core}^{7,10,11)}$. Some redox properties of ferritin using electron transfer mediators such as viologen have also been examined $^{6,8)}$. Recently, the direct electrochemistry of ferritin adsorbed onto an electrode has been reported $^{12-22)}$.

In the formation of solids in biological systems, bio-mineralization provides for the controlled formation of inorganic materials. It is possible that ferritin could be used in protein engineering for nanomaterial synthesis ${ }^{10,11,23-37)}$. A ferritin core could be used for the design of composite nanoparticles for potential magnetic, catalytic and biomedical sensing applications. It has been reported that ferritin was able to catalyze the oxidation and mineralization of cobalt oxyhydroxide within the confines of the protein cage $^{36)}$. Carbon nanotubes were also synthesized using the ferritin core as a catalyst $\mathrm{t}^{25,33-35)}$. The diameter of the carbon nanotubes could be controlled by the diameter of the ferritin core. Thus the direct electron transfer reactions of ferritin could be used to control nanomaterial synthesis by protein engineering. The immobilization of ferritin onto the electrode surface and the electrochemically-regulated iron uptake and release of the immobilized ferritin are fundamental processes that must be understood in order to control nanomaterial synthesis using ferritin. Furthermore, it should be understood that the redox reaction of ferritin is a typical model of nano-space electrochemistry, because the redox reaction occurs in the nano-space cavity $(c a .8 \mathrm{~nm}$ in diameter) of the ferritin shell.

In this article, the author describes the electrode reactions of ferritin-immobilized electrodes based on both self-assembled monolayer (SAM)-modified gold and polypeptide-modified ITO electrodes.

\section{Ferritin-immobilized electrode}

\subsection{Ferritin on SAMs-modified gold electrodes}

A single crystal of gold $\mathrm{Au}(111)$ was used as the working electrode, which was prepared by the method of Clavilier et al. ${ }^{38)}$. The $\mathrm{Au}(111)$ electrode was pretreated by flame-annealing and quenching in ultra-pure water saturated with hydrogen prior to the surface modification. The SAMs were formed by immersing the pretreated electrode into

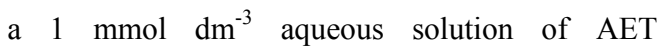
(2-aminoethanthiol, $95 \%$, Tokyo Kasei), AHT (6-amino-1-hexanethiol, 90 \%, Dojin Chem. Co.), AOT (8-amino-1-octanethiol, $90 \%$, Dojin Chem. Co.), AUT (11-amino-1-undecanethiol, $90 \%$, Dojin Chem. Co.), CPT (5-carboxy-1-pentanethiol, Dojin Chem.) or HHT (6-hexanethiol, Dojin Chem.), or an ethanol solution of HT (1-hexanethiol, Tokyo Kasei), respectively, for 20 min. The surface coverage of AET, AHT, AOT, AUT, CPT, HHT and HT onto the Au(111) electrodes was evaluated to be $7.4-7.6 \times 10^{-10}$ $\mathrm{mol} \mathrm{cm}{ }^{-2}$ from the results of the charge integration of the reductive desorption curve on voltammograms obtained in $0.5 \mathrm{~mol} \mathrm{dm}^{-3} \mathrm{KOH}$ 
solution ${ }^{39)}$, indicating that full coverage monolayers were formed on the $\mathrm{Au}(111)$ surface. To immobilize the ferritin onto the SAMs-modified $\mathrm{Au}(111)$ electrode surface, the modified gold electrodes were immersed into a phosphate buffer solution of $2 \mu \mathrm{mol} \mathrm{dm}{ }^{-3}$ ferritin. Prior to the use of the ferritin for immobilization, the ferritin (from horse spleen, Sigma) was purified by size exclusion chromatography to remove free iron ions ${ }^{6}$.

Tapping-mode AFM (atomic force microscopy) was used for the characterization of the ferritin-immobilized surface. A substrate of vapor-deposited gold film on mica (gold/mica) was used for the AFM measurements. The surface of the gold/mica was characterized to be a $\mathrm{Au}(111)$ rich surface. Fig. 1 shows an AFM image of the surface of the gold/mica surface modified with AHT, followed by immersion into a $2 \mu \mathrm{m} \mathrm{dm}^{-3}$ ferritin solution for $60 \mathrm{~min}$. Ferritin molecules covered the whole surface, and no aggregated ferritin was observed on the surface. The ferritin molecules were densely packed like a full monolayer, but were not ordered like a hexagonal packing pattern. The diameter of each ferritin molecule was evaluated to be $12-13 \mathrm{~nm}$ after accounting for distortions due to the shape of the

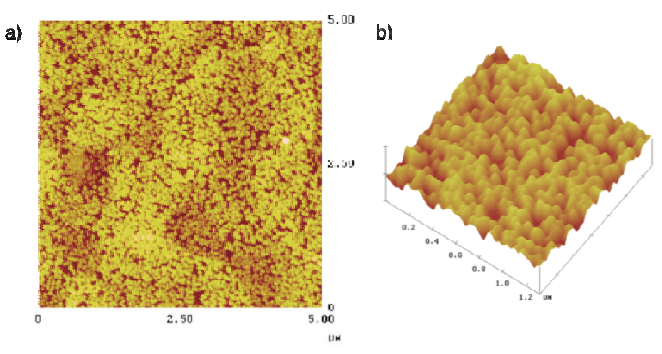

Fig. 1. Tapping-mode AFM images of ferritin molecules immobilized onto an AHT-modified gold electrode. probe tip, which is comparable to the expected $\sim 12 \mathrm{~nm}$ diameter determined from X-ray diffraction ${ }^{1)}$.

AFM images of the ferritin adsorbed onto AET, AOT and AUT-modified gold/mica were almost the same as the AFM image observed on the AHT-modified gold/mica shown in Fig. 1. The ferritin molecules were packed densely into an almost full monolayer packing. There was no chain length dependence of the amino alkane thiols on the AFM images. On the other hand, the ferritin molecules on the gold/mica modified with HHT, CPT and HT were not densely packed from the results of the AFM images. An electrostatic interaction between the protein and the electrode surface is the key factor in immobilizing the protein onto the electrode surface. The isoelectric point of horse spleen ferritin has been reported to be $4.1-5.1^{5)}$, indicating that the ferritin molecule has a negative charge in a neutral buffer solution. Therefore, it is clear that the ferritin was well immobilized onto the gold surface modified with alkane thiol with an amino terminal group via electrostatic interactions.

QCM (quartz crystal microbalance) measurement is highly sensitive to mass changes ${ }^{40)}$. The surface coverage of ferritin on the electrode was investigated using a gold film deposited onto polished quartz crystals with a $27 \mathrm{MHz}$ fundamental resonance frequency. The frequency decrease reached $1615 \mathrm{~Hz}$ after the addition of $8 \mu \mathrm{L}$ of $2 \mu \mathrm{mol} \mathrm{dm} \mathrm{dm}^{-3}$ ferritin into a phosphate buffer solution of $8 \mathrm{~mL}$ at $25{ }^{\circ} \mathrm{C}$, corresponding to a mass change of $0.97 \mu \mathrm{g} \mathrm{cm}^{-2}$. The observed mass change was in good agreement with the expected value $\left(0.9 \mu \mathrm{g} \mathrm{cm} \mathrm{cm}^{-2}\right)$ based on the 
theoretical number of ferritin molecules $\left(8.0 \times 10^{11}\right.$ molecules $\mathrm{cm}^{-2}$ ) as a simple model for monolayer packing on a planar substrate. The AFM results also supported the QCM results.

\subsection{Ferritin on a polypeptides-modified ITO} electrodes

An ITO electrode (from Kinoene Optics Corp., Japan or Kuramoto Corp. Japan) was used, which was cleaned by ultra sonication in a $1 \%$ aqueous New-Vista (AIC Corp.) solution to fully prepare the hydrophilic surface. Poly-(L-lysine) (PLL, MW $=80,000$ and 84,000 Da, Sigma) and poly-(L-arginine) (PLA, MW = 94,000 Da, Sigma) were used as the polypeptides. Polypeptide-modified ITO electrodes were obtained by immersing the ITO electrodes into a phosphate buffer solution $(\mathrm{pH} 7, \mu=0.1)$ in the presence of $1 \mathrm{mg} \mathrm{mL}^{-1}$ of the polypeptide of interest. The modification of the ITO surfaces with PLL and PLA were saturated at immersion time $c a .10 \mathrm{~min}$. The PLL- and PLA-modified ITO electrodes were quite stable. The adsorbed PLL and PLA were almost completely removed from the electrode surfaces by washing with an

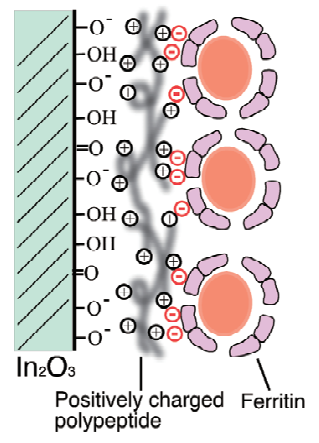

Fig. 2. Schematic illustration of the electrostatic immobilization of ferritin molecules onto a polypeptide-modified ITO electrode. alkaline solution (e.g. $1 \mathrm{~mol} \mathrm{dm} \mathrm{dm}^{-3} \mathrm{NaOH}$ ) under sonication for $20 \mathrm{~min}$; otherwise, the modified electrodes worked durably. After the preparation of the PLL- and PLA-modified ITO electrodes, these electrodes were immersed into $2 \mathrm{mmol} \mathrm{dm}^{-3}$ ferritin solution. The saturated modification of ferritin was reached after an immersion time of approximately $30 \quad \min . \quad$ A schematic representation of the electrostatic immobilization of ferritin molecules onto a polypeptide modified ITO electrode is shown in Fig. 2.

Fig. 3 shows the surface morphology of a PLL-modified ITO electrode (polished ITO) and a ferritin immobilized PLL-modified ITO using tapping-mode AFM measurements. The ITO and PLL-modified ITO electrode surfaces were flat at the atomic level. After the ferritin modification, a monolayer of ferritin molecules adsorbed onto the surface was observed. The size of each ferritin molecule was evaluated at approximately 11 ( \pm 1.5) $\mathrm{nm}$ in diameter, which was comparable to the expected $\sim 12 \mathrm{~nm}$ diameter determined from X-ray diffraction ${ }^{1)}$. These results are similar to the results obtained with SAMs-modified gold electrodes.

The electrostatic interaction of a positively-charged polypeptide with ferritin was demonstrated by zeta potential measurements ${ }^{41)}$. The zeta potential of $6 \mu \mathrm{mol} \mathrm{dm} \mathrm{dm}^{-3}$ ferritin in a phosphate buffer solution $(\mathrm{pH} 7, \mu=0.1)$ was evaluated to be $-8.34 \mathrm{mV}$. The zeta potential changed to -8.08 and $-4.52 \mathrm{mV}$ when 0.6 and $3.0 \mu \mathrm{mol} \mathrm{dm}{ }^{-3}$ PLL was added to the phosphate buffer solution of $6 \mu \mathrm{mol} \mathrm{dm} \mathrm{dm}^{-3}$ ferritin. These zeta potential changes after PLL addition support electrostatic interactions between the 
ferritin and PLL.

\section{Electrode reaction of ferritin}

\subsection{SAMs-modified gold electrodes}

Fig. 4 shows cyclic voltammograms of ferritin-immobilized electrodes modified with self-assembled monolayers (SAMs)-modified gold electrodes. Well-defined redox waves representing the ferritin immobilized on the AHT-modified gold electrode were observed. These results show that an electron transfer reaction occurred between the ferritin and the electrode surface. At the HHT-modified gold electrode, no redox response of the ferritin was observed. In the case of CPT- and HT-modified gold electrodes, redox waves representing ferritin were observed. The obtained redox peak currents were lower than those observed for the ATH-modified electrode. The redox peak current dependence of the SAM-modified gold electrode was in good agreement with the results of ferritin coverage obtained from the AFM measurements.

The anodic and cathodic peak potentials on the cyclic voltammograms of ferritin immobilized onto AHT were observed around -0.22 and $-0.35 \mathrm{~V}$ (vs.

a)
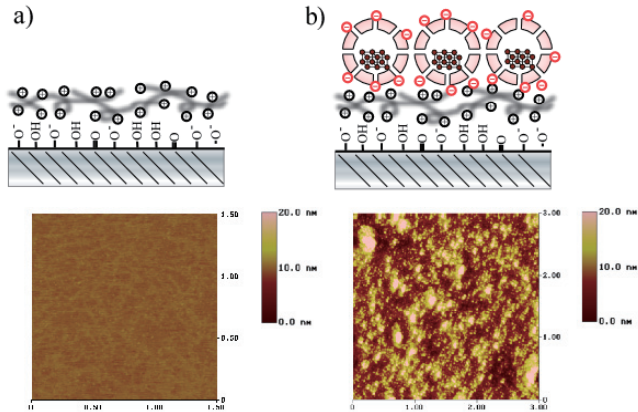

Fig. 3. Tapping-mode AFM images of a) a PLL-modified ITO electrode and b) ferritin immobilized onto an ITO electrode modified with PLL.
$\mathrm{Ag} / \mathrm{AgCl}($ saturated $\mathrm{KCl})$ ), respectively, at a potential sweep rate of $50 \mathrm{mV} \mathrm{s}^{-1}$. These values were not significantly different from those reported for ferritin adsorbed onto ITO and polypeptide-modified ITO electrodes ${ }^{13,20)}$. However, the values obtained are more positive than the reported redox potential (approximately $-0.41 \mathrm{~V}$ vs $\mathrm{Ag} / \mathrm{AgCl}$ (saturated $\mathrm{KCl}$ )) for a solution of ferritin using mediated coulometry). This difference would be due to the slight conformational change of ferritin that occurs during its immobilization onto the electrode.

As described above, there was no chain length dependence of the amino alkane thiols on the AFM images. On the other hand, chain length dependence was observed for the electrochemical behavior of ferritin immobilized electrodes modified with AET, AHT, AOT and AUT. The peak current in the voltammograms decreased with increasing chain length. Eventually, no redox response of the ferritin was observed on the AUT-modified gold electrode.
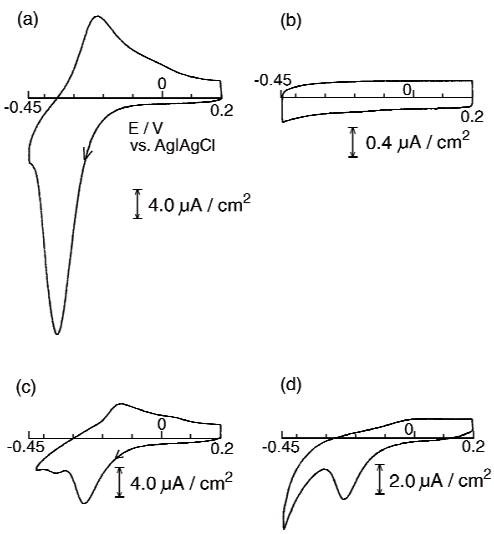

Fig. 4. Cyclic voltammograms at ferritin immobilized onto gold electrodes modified with a) AHT, b) HHT, c) CPT, and d) HT in a phosphate buffer solution ( $\mathrm{pH} 7, \mu=0.1)$. Potential sweep rate: $50 \mathrm{mV} \mathrm{s}^{-1}$. Temperature: $25{ }^{\circ} \mathrm{C}$. 
The ferritin immobilized onto the AHT-modified gold electrode was active electrochemically. Here, the number of iron atoms in the ferritin core per ferritin molecule was determined to be $c a$. 3000 using flame atomic absorption spectroscopy. The value of the charge flow with the reduction reaction for the iron atoms during electrolysis enabled us to determine the surface coverage of ferritin immobilized onto the modified electrode. The electrolysis was carried out at $-0.4 \mathrm{~V}$, which was sufficient to reduce it. Based on 3000 iron atoms per ferritin molecule together with the theoretical number of $8.0 \times 10^{11}$ ferritin molecules $\mathrm{cm}^{-2}, 3.9 \times 10^{2} \mu \mathrm{C} \mathrm{cm}^{-2}$ was calculated as the theoretical value of charge flow.

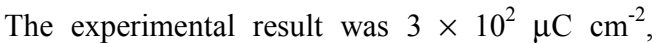
which corresponded to approximately $80 \%$ of the expected theoretical value. The discrepancy between the experimental and theoretical values was due to two reasons. First, the desorption of AHT and/or ferritin from the surface during electrolysis was observed. The surface coverage of AHT after electrolysis was $6.8 \times 10^{-10} \mathrm{~mol} \mathrm{~cm}{ }^{-2}$, which corresponded to $89 \%$ of the full coverage. The second reason was that the electrochemical activity depended on the number of iron atoms in the ferritin core. No redox reaction of ferritin was observed if the ferritin contained less than $c a$. 350 iron atoms ${ }^{17)}$. This result suggested that
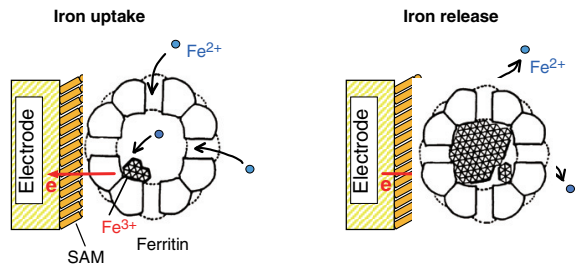

Fig. 5. Schematic illustration of the iron uptake and release by ferritin immobilized onto an AHT-modified gold electrode.

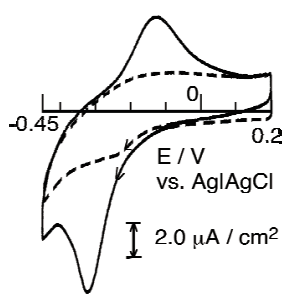

Fig. 6. Cyclic voltammograms for the demonstration of the iron uptake and release by ferritin immobilized onto an AHT-modified gold electrode in a phosphate buffer solution $(\mathrm{pH} 7$, $\mu=0.1$ ) in the presence of $1 \mathrm{mmol} \mathrm{dm}^{-3}$ NTA after iron uptake (solid line), and in a phosphate buffer solution before iron uptake (broken line) at $25^{\circ} \mathrm{C}$. Potential sweep rate: $50 \mathrm{mV} \mathrm{s}^{-1}$.

approximately $10 \%$ of the 3000 iron atoms cannot be reduced by electrolysis and are still present in the ferritin core.

Electrochemically regulated iron uptake and release were demonstrated as shown in Fig. 5. The redox peak currents of ferritin immobilized on an AHT-modified gold electrode decreased gradually with potential cycling in a buffer solution. As described in the previous section, the peak current decreased significantly when the electrode potential was held at $-0.4 \mathrm{~V}$ during electrolysis for a few minutes. Eventually, no redox response for ferritin could be observed. These results indicate the iron release controlled by the electrode potential. On the other hand, the redox wave of ferritin was observed again after the electrode was held at $0 \mathrm{~V}$ in a phosphate buffer solution of $10 \mu \mathrm{mol} \mathrm{dm}{ }^{-3} \mathrm{FeSO}_{4}$ for $30 \mathrm{~min}$ (Fig. 6). The observed redox wave could be attributed to iron atoms reincorporated into the ferritin shell.

\subsection{Polypeptides-modified ITO electrodes}

Typical cyclic voltammograms for ferritin after the PLL- and PLA-modified ITO electrodes were 
immersed into a phosphate buffer solution of $2 \mu \mathrm{mol} \mathrm{dm}{ }^{-3}$ ferritin for $60 \mathrm{~min}$ are shown in Fig. 7 . Well-defined redox waves representing ferritin were observed. At the PLL-modified ITO electrodes, oxidation and reduction peaks were observed around -0.12 and $-0.22 \mathrm{~V}$ (vs. $\mathrm{Ag} / \mathrm{AgCl}$ (saturated $\mathrm{KCl})$ ), respectively, at a potential sweep rate of $50 \mathrm{mV} \mathrm{s}^{-1}$. Similar results were obtained at the PLA-modified ITO electrode. No redox response for ferritin was obtained in the buffer solution after immersion into the ferritin solution when the ITO electrode was not modified with PLL or PLA.

The redox peak potentials at the PLL- and PLA-modified ITO electrodes were similar to those obtained at the AHT-modified gold electrode. However, a difference in the shape of the voltammetric wave was observed. At SAMs-modified gold electrodes such as an AHT-modified electrode, the reduction peak current was larger than the oxidation peak. On the other hand, at the ferritin modified PLL- and PLA-modified ITO electrodes, the reduction and oxidation peak currents showed almost the same peak current. The oxidation and reduction peak
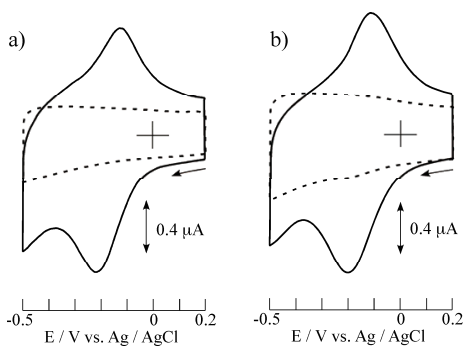

Fig. 7. Cyclic voltammograms of ferritin immobilized onto a) PLL- and b) PLA-modified ITO electrodes $\left(0.25 \mathrm{~cm}^{2}\right)$ in a phosphate buffer solution $(\mathrm{pH} 7, \mu=0.1)$ at $25^{\circ} \mathrm{C}$. Potential sweep rate: $50 \mathrm{mV} \mathrm{s}^{-1}$. The cyclic voltammograms at PLL- and PLA-modified ITO electrodes are shown as broken lines. currents gradually decreased with increasing potential cycling in the buffer solution. The peak currents did not decrease when the electrode potential was held at $0.2 \mathrm{~V}$. On the other hand, the peak current decreased significantly after the electrode potential was held at $-0.5 \mathrm{~V}$. This decrease in peak current was enhanced in the presence of nitriloacetic acid (NTA) as an iron chelator. To determine the surface coverage of ferritin on the PLL-modified ITO electrode, the concentration of $\mathrm{Fe}$ (II)-NTA complex was evaluated by ICP-AES measurements, after the potential-controlled electrolysis of the ferritin immobilized electrode $\left(100 \mathrm{~cm}^{2}\right)$ was performed at $-0.5 \mathrm{~V}$ for $60 \mathrm{~min}$ in the presence of $0.1 \mathrm{mmol} \mathrm{dm}^{-3}$ NTA. The results on the concentration of the Fe-NTA complex, together with the fact that the number of iron atoms per ferritin molecule used, and the fact that the roughness factor of the surface $(1.1-1.3)$ was approximately $3.3 \times 10^{3}$ atoms indicated that the surface coverage of ferritin was 9 - $13 \times 10^{11}$ molecules $\mathrm{cm}^{-2}$. This calculated surface coverage at the PLL-modified ITO electrode was close to the theoretically expected value of $8.0 \times 10^{11}$ molecules $\mathrm{cm}^{-2}$.

Voltammograms at various potential sweep rates were obtained from individual ferritin modified electrodes. Both cathodic and anodic peak currents were proportional to the potential sweep rates at a sweep range of $20-200 \mathrm{mV} \mathrm{s}^{-1}$ (Fig. 8). It is understood that the cathodic peak current increased linearly with an increasing potential sweep rate, because $\mathrm{Fe}(\mathrm{III})$ atoms exist as a crystal core like a ferrihydrite phosphate structure. The reduced $\mathrm{Fe}$ (II) atoms would still sit in the same position in the crystal core surface, 


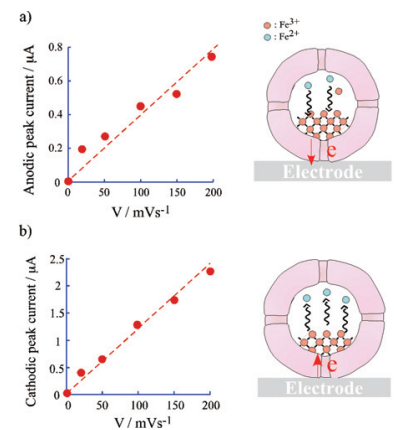

Fig. 8. Plots of a) anodic and b) cathodic peak currents vs. the potential sweep rates from cyclic voltammograms of ferritin immobilized onto PLL-modified ITO electrodes $\left(0.25 \mathrm{~cm}^{2}\right)$ in a phosphate buffer solution ( $\mathrm{pH} 7, \mu=0.1)$ at 25 ${ }^{\circ} \mathrm{C}$.

or would be released from the core surface, because the solubility of $\mathrm{Fe}(\mathrm{II})\left(\mathrm{Fe}(\mathrm{OH})_{2}: K_{\mathrm{sp}} \approx\right.$ $\left.10^{-15}(\mathrm{~mol} \mathrm{dm})^{-3}\right)$ is much higher than that of $\mathrm{Fe}(\mathrm{III})\left(\mathrm{Fe}(\mathrm{OH})_{3}: K_{\mathrm{sp}} \approx 10^{-39}\left(\mathrm{~mol} \mathrm{dm}^{-3}\right)^{3}\right)$ under physiological $\mathrm{pH}$ values ${ }^{42)}$. Thus, given the positive potential sweep, it was expected that the electrode reaction behavior would show a diffusion-controlled electrode reaction, or a reaction type mixed with diffusion-controlled and adsorbed specie reaction types. The obtained results showed a linear relationship between the anodic peak currents and the potential sweep rates. This behavior would be due to the thin-layer electrochemical behavior. Considering that the released $\mathrm{Fe}(\mathrm{II})$ irons exist in a protein shell with a ca. $8 \mathrm{~nm}$ inner diameter, the finite diffusion layer (inner diameter of $8 \mathrm{~nm}$ ) would react at $c a .3 \times 10^{-8}$ $\mathrm{s}$ based on the equation of $x^{2}=2 D t$, where $x$ is the displacement, $t$ is time and $D$ is the diffusion coefficient. This time $\left(3 \times 10^{-8} \mathrm{~s}\right)$ is much smaller than time scale of the cyclic voltammetry used in this study. Taking into account the above description, it is clear that linear relationship between the anodic peak currents and the potential sweep rates was observed.

From the result that the peak current was proportional to the potential sweep rates, the charge flows during the oxidation and reduction reactions were calculated from the peak areas in the voltammograms. During the first cycle of the cyclic voltammetric measurements, the charge flow values in the cathodic and anodic peaks were $7.4 \times 10^{-6}$ and $5.0 \times 10^{-6} \mathrm{C} \mathrm{cm}^{-2}$, respectively, indicating that $7.7 \times 10^{-11}$ and $5.2 \times 10^{-11} \mathrm{~mol} \mathrm{dm}^{-3}$ of iron atoms had reacted. Taking account into the surface coverage $\left(9-13 \times 10^{11}\right.$ molecules $\mathrm{cm}^{-2}$ ) of ferritin as described previously, $43( \pm 8) \mathrm{Fe}(\mathrm{III})$ ions per ferritin molecules were reduced and $29( \pm 5) \mathrm{Fe}(\mathrm{II})$ ions per molecules were oxidized. The number of iron ions reacting in the ferritin cavity during the redox reaction was significantly smaller than the expected value based on the number of iron ions at the ferritin core surface. The total charge in the ferritin cavity should be maintained at neutral during the redox reaction of ferritin. In order to compensate for the change in the charge of the ferritin cavity, in other words to maintain electroneutrality in the cavity, both ion uptake and/or release passing through the ion channels of ferritin must occur. This compensatory ion uptake and/or release would be the rate-determining factor, and thus the number of iron ions actually related to the redox reactions would be significantly smaller than expected.

\subsection{EQCM at PLL-modified ITO electrode}

An ITO film was deposited onto an AT-cut quartz crystal with a $9 \mathrm{MHz}$ fundamental 
resonance frequency (ITO-QCM) and followed by surface polishing, which was obtained from Seiko EG\&G. This electrode was used as the working electrode for EQCM measurements. The surface of the ITO-QCM $\left(0.196 \mathrm{~cm}^{-2}\right)$ was cleaned with UV-ozone treatment, followed by ultra sonication in $1 \%$ New-Vista aqueous solution. The cleaned surface was modified with PLL (concentration $1 \mathrm{mg} \mathrm{mL}^{-1}, \mathrm{MW}=500 \sim 2000$ ) for $30 \mathrm{~min}$, and was then modified with ferritin (concentration $0.1 \mu \mathrm{mol} \mathrm{dm}{ }^{-3}$ ) for $60 \mathrm{~min}$.

Fig. 9 shows the cyclic voltammogram and frequency change in the EQCM measurements at the ferritin modified ITO-QCM electrode in a phosphate buffer solution ${ }^{43)}$. The mass decreased at around $-0.15 \mathrm{~V}(v s . \mathrm{Ag} / \mathrm{AgCl}$ (saturated $\mathrm{KCl})$ ). Furthermore, a reduction current was observed from around $-0.15 \mathrm{~V}$. The mass decreased from -0.15 to $-0.5 \mathrm{~V}$, and from -0.5 to $-0.25 \mathrm{~V}$ in reversing potential. In the reversing potential, the mass increased from -0.25 to $0.2 \mathrm{~V}$. Ultimately, the total mass change before and after the potential cycle was $5.9 \mathrm{~Hz}$. The charge flow during the reduction reactions was calculated to be $c a .12 \times$ $10^{-6} \mathrm{C} \mathrm{cm}^{-2}$, meaning that $7.1 \times 10^{-9} \mathrm{~g} \mathrm{~cm}^{-2} \mathrm{Fe}$ (III) was reduced. On the other hand, we could

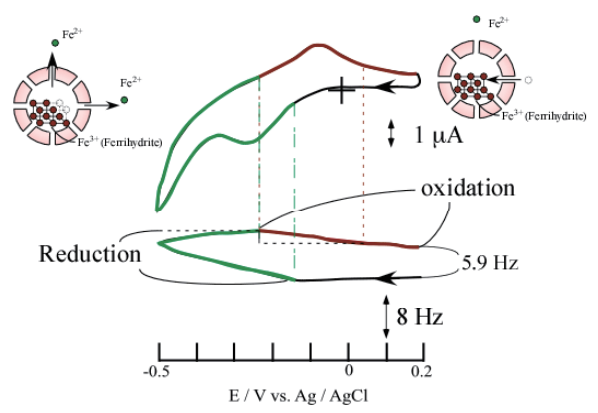

Fig. 9. Cyclic voltammograms and frequency changes at ferritin immobilized onto ITO electrodes modified with PLL (M.W.: 500-2,000) in a phosphate buffer solution ( $\mathrm{pH} 7.0)$ at $20{ }^{\circ} \mathrm{C}$. Potential sweep rate: $50 \mathrm{mV} \mathrm{s}^{-1}$. estimate the total mass change after the reduction reaction. In the potential range during the reduction reaction, the mass change was $3.4 \mathrm{~Hz}$ (at $0.196 \mathrm{~cm}^{-2}$ ), corresponding the mass change of $19 \times 10^{-9} \mathrm{~g} \mathrm{~cm}^{-2}$. The discrepancy in mass change between the voltammetric measurements based on electrode reactions and the QCM was due to the core structure. The ferritin core is a ferrihydrite like structure composed of $\mathrm{Fe}, \mathrm{O}, \mathrm{H}$ and $\mathrm{P}$ atoms. The $\mathrm{Fe}$ atom is the only active one in electrochemistry. Thus, the mass of ferritin core due to the mass ratio of $\mathrm{Fe}:(\mathrm{O}+\mathrm{H}+\mathrm{P})$ would be approximately $4: 6$.

The frequency change before and after ferritin modification was $340 \mathrm{~Hz}$, which corresponds to $1.9( \pm 0.2) \times 10^{-6} \mathrm{~g} \mathrm{~cm}^{-2}$. Here, we assumed that the ferritin molecular weight with ferrihydrite crystal containing 3300 iron ions was $9.7 \times 10^{5} \mathrm{Da}^{44)}$, and the ferritin coverage on the electrode surface was calculated to be $12( \pm 2) \times$ $10^{11}$ molecules $\mathrm{cm}^{-2}$. This obtained result was in good agreement with the surface coverage value (9 - $13 \times 10^{11}$ molecules $\mathrm{cm}^{-2}$ ) obtained from PLL modified ITO electrodes described in the previous section.

Thus, the total mass change before and after the potential cycle was $5.9 \mathrm{~Hz}$ as described previously. Approximately $2.2 \mathrm{~Hz}$ (which calculated from $1 / 2.7$ of $5.9 \mathrm{~Hz}$ ) was due to $\mathrm{Fe}(\mathrm{II})$ release. This mass change due to the $\mathrm{Fe}$ (II) release was evaluated to be $1.3 \times 10^{14}$ atoms $\mathrm{cm}^{-2}$. Here, using the surface coverage of ferritin of $12( \pm 2) \times$ $10^{11}$ molecules $\mathrm{cm}^{-2}$, the $\mathrm{Fe}(\mathrm{II})$ release was calculated to be $110( \pm 20)$ atoms per molecule. 


\subsection{Reversible fine structural change and} electrochemical response

It is well-known that the ferritin protein structure is very stable against temperature up to ca. $80{ }^{\circ} \mathrm{C}^{1)}$. It has been observed that reversible fine structural changes in the ferritin protein occur at ca. $25{ }^{\circ} \mathrm{C}$ using fluorescent spectroscopy and $\mathrm{CD}$ (circular dichroism) measurements ${ }^{45}$.

The ferritin protein shows peaks around 210 and $222 \mathrm{~nm}$ in CD spectra based on the $\alpha$-helix of the protein. Fig. 10a,b shows a peak intensity at $210 \mathrm{~nm}$ in the CD spectra of ferritin in the presence and absence of $0.05 \mu \mathrm{mol} \mathrm{dm}^{-3}$ PLL (MW $=84,000 \mathrm{Da}$ ). Both results showed a biphasic behavior around $25{ }^{\circ} \mathrm{C}$, which was reversible. This result suggests that a reversible, fine structural change in the ferritin protein occurs around $25^{\circ} \mathrm{C}$. Furthermore, this structural change was inhibited in the presence of PLL, because the degree of the biphasic change in ferritin with PLL was smaller than that without PLL. The fluorescent results were similar to the results from the CD. Ferritin protein shows a peak around $325 \mathrm{~nm}$ in its fluorescent spectra, which is due to the 24 tryptophan residues in the ferritin protein as

$$
\text { A) }
$$
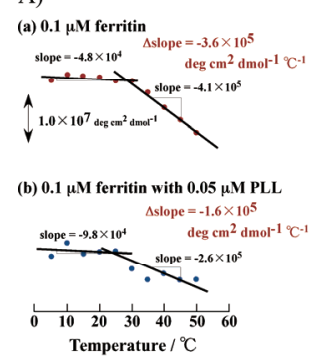

Fig. 10. Temperature dependence of peak intensity A) at $210 \mathrm{~nm}$ in the CD spectra, and B) in the fluorescence emission spectra of (a) ca. 0.1 $\mu \mathrm{mol} \mathrm{dm} \mathrm{dm}^{-3}$ ferritin, and (b) ca. $0.1 \mathrm{~mol} \mathrm{dm}^{-3}$ ferritin with $0.05 \mu \mathrm{mol} \mathrm{dm} \mathrm{dm}^{-3}$ PLL in a phosphate buffer solution ( $\mathrm{pH} 7)$. shown in Fig. 11. In particular, 10 residues of tryptophan are located around the ion channel of ferritin (6 residues around the hydrophilic 3-fold channels and 4 residues around the hydrophobic 4-fold channels). Fig. 10c,d shows a peak intensity at $325 \mathrm{~nm}$ in the fluorescent spectra of ferritin in the presence and absence of $0.05 \mu \mathrm{mol} \mathrm{dm}{ }^{-3}$ PLL. Both results showed a biphasic behavior around $25{ }^{\circ} \mathrm{C}$, which was also reversible. Furthermore, this structural change was also inhibited in the presence of PLL, because the degree of the biphasic change in ferritin with PLL was smaller than that without PLL. Aspartic and glutamic acid residues, which have a negative charge in neutral solution to bind with PLL via electrostatic interactions, are present over the entire molecular surface without any specific localization, as shown in Fig. 12. Furthermore, the molecular length of PLL (MW = 84,000 Da) was approximately 300 times longer than the ferritin diameter $(c a .12 \mathrm{~nm})$. It would be expected that PLL could cover the entire surface of ferritin molecule with electrostatic binding, which would be inhibit the fine structural change in ferritin.
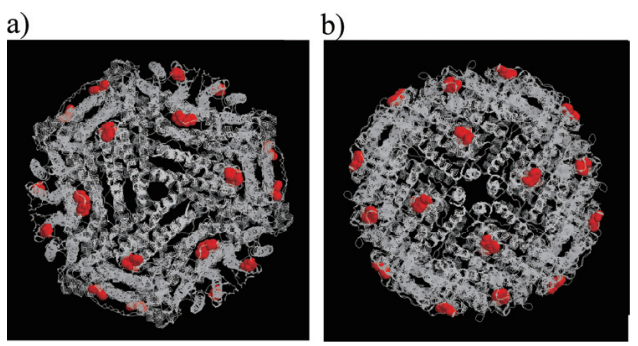

Fig. 11. Schematic representation of a) a three-fold channel and b) a four-fold channel of ferritin and the position of the tryptophan residues. The atomic coordinates have been deposited in the Protein Data Bank with the entry codes 1 MFR for bullfrog M ferritin. 

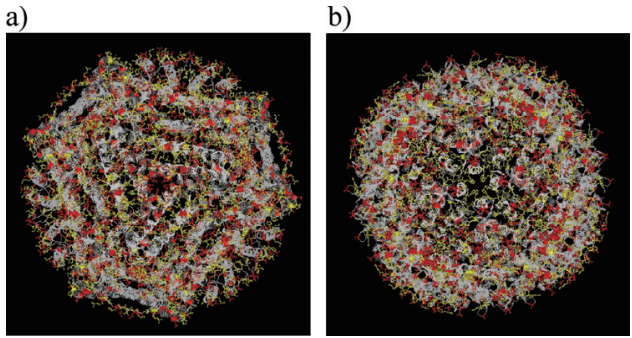

Fig. 12. Schematic representations of a) a three-fold channel and b) a four-fold channel of ferritin and the position of the aspartic acid and glutamic acid residues. The atomic coordinates have been deposited in the Protein Data Bank with the entry codes 1MFR for bullfrog M ferritin.

The effect of this fine structural change on the electrode reaction of ferritin was investigated. Fig. 13 shows cyclic voltammograms of ferritin modified onto PLL-ITO (MW $=84,000 \mathrm{Da}$ ) and AHT-modifid gold electrodes at various temperatures. The peak currents were strongly dependent on the temperature. A plot of the cathodic peak currents vs. temperature is shown in Fig. 14a. Biphasic behavior around $25{ }^{\circ} \mathrm{C}$ was observed. Fig. 14b shows a plot of the cathodic peaks obtained from cyclic voltammograms of ferritin immobilized onto AHT-modified gold electrodes. A biphasic behavior was also observed around $25{ }^{\circ} \mathrm{C}$, which was stronger in comparison to the PLL-ITO electrode, because the change in the slope of the peak current over the temperature was much larger. From the results of the QCM and electrochemical measurements, the peak current decreasing with increasing temperature over $25-50{ }^{\circ} \mathrm{C}$ was not due to ferritin release from the surface. Furthermore, the biphasic behavior around $25{ }^{\circ} \mathrm{C}$ was not explained by the temperature dependence of the ion-product constant of water. It was concluded that this
A)

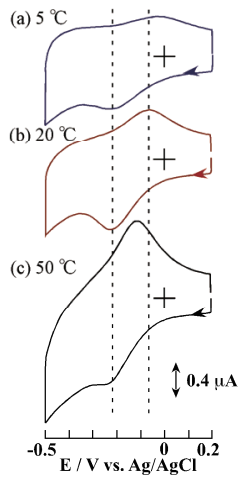

B)

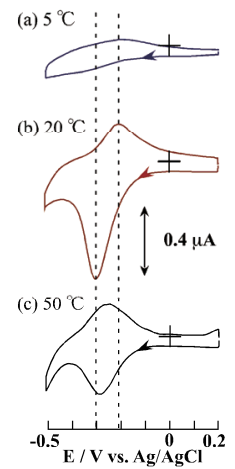

Fig. 13. Cyclic voltammograms of ferritin immobilized onto A) PLL-modified ITO $(0.25$ $\left.\mathrm{cm}^{2}\right)$ and B) AHT-modified gold $\left(0.059 \mathrm{~cm}^{2}\right)$ electrodes in a phosphate buffer solution $(\mathrm{pH} 7)$ at (a) 5 , (b) 20 and (c) $50{ }^{\circ} \mathrm{C}$. Potential sweep rate: $50 \mathrm{mV} \mathrm{s}^{-1}$.

biphasic behavior would be due to ion channel structural changes induced by the fine structural change of ferritin as detected by the $\mathrm{CD}$ and fluorescent measurements. As mentioned in the previous section, the total charge in the ferritin cavity should be maintained at neutrality during the redox reaction of ferritin. In order to compensate for changes in the charge in the ferritin cavity, ion uptake and/or relese passing through the ion channels of ferritin would occur. The energy for an ion passing through the ion channels would be change around $25{ }^{\circ} \mathrm{C}$, which was the temperature induced the reversible fine structural
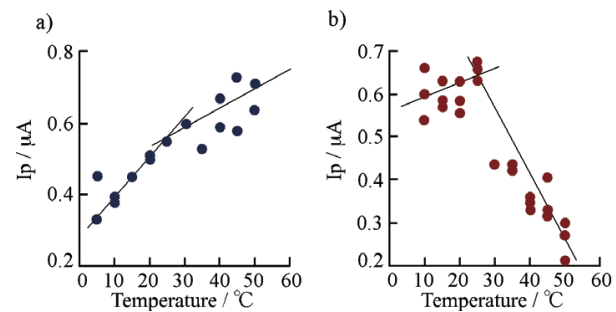

Fig. 14. Cathodic peak currents of ferritin immobilized onto a) PLL-modified ITO and b) AHT-modified gold electrodes as a function of the temperature. 
a)

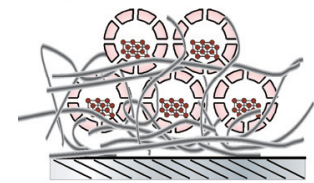

b)

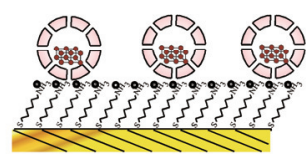

Fig. 15. Schematic representation of ferritin immobilized onto a) PLL-modified ITO and b) AHT-modified gold electrodes.

change in ferritin. A difference in the biphasic behavior of ferritin between PLL-modified ITO and AHT-modified gold electrodes was observed, which would be due to the difference in the microenvironment of ferritin at the electrode surface. At the PLL-modified ITO surface, the ferritin molecule binds to PLL molecular wire via electrostatic interaction (Fig. 15a), which are like a three-dimensional binding. On the other hand, at the AHT-modified gold surface, the ferritin molecule binds to a narrow area of the surface via electrostatic interactions (Fig. 15b), which are like a zero-dimensional binding. The fact that structural change was inhibited in the presence of PLL in the solution phase detected from the CD and fluorescent measurements, such a three-dimensional interaction of the ferritin molecule with PLL at the surface, would also inhibit the fine structural change.

\section{Conclusions}

Our recent investigation into the redox reactions of ferritin at various electrode surfaces has been described in this review. The redox reaction occurs in the ferritin cavity. The cavity is $c a .8 \mathrm{~nm}$ in diameter, and connects with the outside of the protein shell via ion channels. The redox reaction of ferritin represents a typical model of nano-space electrochemistry. The redox reaction was strongly influenced by fine structural changes of the ion channels induced by temperature and the binding of the ferritin molecule with polypeptides via electrostatic interactions. These electrochemical results suggest that in nano-space electrochemistry, a channel connecting the inside and the outside of the nano-space plays an important role for total redox reaction behavior.

\section{Acknowledgements}

This work was supported in part by a Grant-in-Aid for Young Scientists B and Scientific Research C from the Ministry of Education, Culture, Sports, Science and Technology (MEXT), Japan. The author also acknowledges grants from the Advanced Technology Institute Foundation, Iketani Science and Technology Foundation, Asahi Glass Foundation and Nippon Sheet Glass Foundation for Materials Science and Engineering. Sincere thanks are extended to all of the collaborators and co-authors of our papers cited in this review, in particular Prof. Isao Taniguchi.

\section{References}

1) P. M. Harrison and T. H. Lille, Iron Carriers and Iron Proteins, VCH Press, New York, 1989.

2) T. G. St. Pierre, P. Chan, K.R. Bauchspiess, J. Webb, S. Betteridge, S. Walton and D. P. E. Dickson, Coord. Chem. Rev., 151, 125 (1996).

3) P. M. Proulx-Curry and N. D. Chasteen, Coord. Chem. Rev., 144, 347 (1995).

4) P. M. Harrison and P. Arosio, Biochim. Biophys. 
Acta, 1275, 161 (1996).

5) P. Arosio, T. G. Adellman and J. W. Drysdale, J. Biol. Chem., 253, 4451 (1978).

6) G. D. Watt, R. B. Frankel and G. C. Papaefthymiou, Proc. Natl. Acad. Sci., 82, 3640 (1985).

7) F. H. A. Kadir, F. K. Al-Massad, S. J. A. Fatemi, H. K. Singh, M. T. Willson and G. R. Moore, Biochem. J., 278, 817 (1991).

8) R. K. Watt, R. B. Frankel and G. D. Watt, Biochemistry, 31, 9673 (1992).

9) X. Liu and E. C. Theil, Acc. Chem. Res., 38, 167 (2005).

10) F. Funk, J.-P. Lenders, R. R. Crichton and W. Schneider, Eur. J. Biochem. 152, 167 (1985).

11) G. D. Watt, D. Jacobs and R. B. Frankel, Proc. Natl. Acad. Sci., 85, 7457 (1988).

12) T. D. Martin, S. A. Monheit, R. J. Niichel, S. C. Peterson, C. H. Campbell and D. C. Zapien, J. Electroanal. Chem., 420, 279 (1997).

13) R. J. Cherry, A. J. Bjornsen and D. C. Zapien, Langmuir, 14, 1971 (1998).

14) M.-S. Pyon, R. J. Cherry, A. J. Bjornsen and D.

C. Zapien, Langmuir, 15, 7040 (1999).

15) D. C. Zapien and M. A. Johnson, $J$. Electroanal. Chem., 494, 114 (2000).

16) F. Marken, D. Partel, C. E. Madden, R. C. Millward and S. Fletcher, New J. Chem., 26, 259 (2002).

17) M. Tominaga and I. Taniguchi, Chem. Lett., 32, 954 (2003).

18) M. Tominaga and I. Taniguchi, Chem. Lett., 704 (2001).

19) M. Tominaga, A. Ohira, Y. Yamaguchi and M. Kunitake, J. Electroanal. Chem., 566, 323 (2004).
20) M. Tominaga, K. Soejima, M. Matsumoto and

I. Taniguchi, J. Electroanal. Chem., 579, 51 (2005).

21) M. Tominaga, K. Miyahara, K. Soejima, S. Nomura, M. Matsumoto and I. Taniguchi, J. Colloid Inter. Sci., 313, 135 (2007).

22) M. Tominaga, K. Soejima and I. Taniguchi, $J$. Electroanal. Chem., 617, 78 (2008).

23) M. T. Klem, M. Young and T. Douglas, Materials Today, 8, 28 (2005).

24) Z. Yang, X. Wang, H. Diao, J. Zhang, H. Li, H. Sun and Z. Guo, Chem. Commun., 3453 (2007).

25) T. Douglas and V.T. Stark, Ionrg. Chem., 39, 1828 (2000).

26) M. Allen, D. Willits, J. Mosolf, M. Young and

T. Douglas, Adv. Mater., 14, 1562 (2002).

27) J. M. Dominguez-Vera and E. Colacio, Inorg. Chem., 42, 6983 (2004).

28) I. Yamashita, Thin Solid Films, 393, 12 (2001).

29) M. Tominaga, A. Ohira, A. Kubo, I. Taniguchi and M. Kunitake, Chem. Commun., 1518 (2004).

30) I. Kim, H.-A. Hosein, D. R. Strongin and T. Douglas, Chem. Mat., 14, 4874 (2002).

31) T. Douglas, E. Strable, D. Willits, A. Aitouchen, M. Libera and M. Yound, Adv. Mater., 14, 415 (2002).

32) S. C. Tsang, J. Qiu, P. J. F. Harris, Q. J. Fu and N. Zhang, Chem. Phys. Lett., 322, 553 (2000).

33) M. Su, Y. Li, B. Maynor, A. Buldum, J. P. Lu and J. Liu, J. Phys. Chem., 104, 6505 (2000).

34) Y. Li, W. Kim, Y. Zhang, M. Rolandi, D. Wang and H. Dai, J. Phys. Chem., 105, 11424 (2001).

35) J.-M. Bonard, P. Chauvin and C. Klinke, Nano Lett., 6, 665 (2002).

36) Y. Zhang, Y. Li, W. Kim, D. Wang and H. Dai, 
App. Phys. A, 74, 325 (2002).

37) M. Tominaga, L. Han, L. Wang, M. M. Maye, J.

Luo, N. Kariuki and C. J. Zhong, J. Nanosci.

Nanotechnol., 4, 708 (2004).

38) J. Clavilier, R. Faure, G. Guinet and R. Durand,

J. Electroanal. Chem., 107, 205 (1980).

39) C. A. Widrig, C. Chung and M. D. Porter, J. Electroanal. Chem., 310, 335 (1991).

40) G. Sauerbrey, Z. Phyzik, 155, 206 (1959).

41) unpublished data.

42) T. Jones, R. Spencer and C. Walsh, Biochem., 17, 4011 (1978).

43) unpublished data.

44) The molecular weight of ferritin with 3300 iron atoms was evaluated from following calculations. Apo-ferritin is consisting from 24 subunits of $c a .19800 \mathrm{Da}$, thus molecular weight of apo-ferritin is $c a .4 .7 \times 10^{5} \mathrm{Da}$. The mass of ferritin core is evaluated from the basis of that ferrihydrite ferritin core is about 2.7 times larger than the mass of iron ions $(c a .3300 \times 55.85 \mathrm{Da})$, which is $5.0 \times 10^{5} \mathrm{Da}$. Thus, the mass of apo-ferritin and its core is ca. $9.7 \times 10^{5} \mathrm{Da}$. The value of 2.7 is calculated from the mass weight ratio of $\mathrm{Fe}\left(7.1 \times 10^{-9} \mathrm{~g} \mathrm{~cm}^{-2}\right)$ to ferrihydrite $\left(19 \times 10^{-9} \mathrm{~g} \mathrm{~cm}^{-2}\right)$ based on EQCM measurement.

45) unpublished data. 